\title{
Effect of Loading Rate on Hen's Eggshell Mechanics
}

\author{
Jan Trnka ${ }^{1}$, Jaroslav Buchar ${ }^{2}$, Libor Severa ${ }^{2}$, Sárka Nedomová ${ }^{2} \&$ Pavla Stoklasová $^{1}$ \\ ${ }^{1}$ Institute of Thermomechanics AS CR, v. v. i, Praha, Czech Republic \\ ${ }^{2}$ Department of Physics, Mendel University in Brno, Brno, Czech Republic \\ ${ }^{3}$ Department of Food Technology, Mendel University in Brno, Brno, Czech Republic \\ Correspondence: Jan Trnka, Institute of Thermomechanics AS CR, v. v. i, Dolejškova 1402/5, Praha 18200, \\ Czech Republic. E-mail: trnka@it.cas.cz
}

Received: June 29, 2012 Accepted: August 29, 2012 Online Published: October 26, 2012

doi:10.5539/jfr.v1n4p96 URL: http://dx.doi.org/10.5539/jfr.v1n4p96

\begin{abstract}
The study is focused on analysis of mechanical behavior of hen's eggshell expressed in terms of average rupture force and corresponding deformation. Some other physical properties such as mass, length, diameter, geometric mean diameter, surface area, sphericity, and volume were also evaluated. The egg samples were compressed along their $X$ and $Z$-axes. Two different experimental methods were used: compression between two plates (loading rates $0.0167,0.167$, and $1.67 \mathrm{~mm} / \mathrm{s}$ ) and impact of a free-falling cylindrical bar (loading rates up to 17 $\mathrm{mm} / \mathrm{s}$ ). Surface displacement and surface velocity were measured using the laser-vibrometer. The increase in rupture force with loading rate was observed for loading in all direction (along main axes). Dependence of the rupture force on loading rate was quantified and described. The highest rupture force was obtained when the eggs were loaded along the $X$-axis. Compression along the $Z$-axis required the least compressive force to break the eggshells.
\end{abstract}

Keywords: eggshell, strength, elasticity, numerical simulation

\section{Introduction}

A chicken egg is a packaged food and an important quality aspect of the packaged egg material is the mechanical strength of the eggshell (Altuntaş \& Şekeroğlu, 2008). Breaking of the eggshell is due to forces acting on the eggs under quasi-static conditions, as at the bottom of a pile of loaded trays, but the greater part occurs under dynamic conditions: when an egg falls on to the cage floor at oviposition, when it rolls out of the cage and hits another on the rollaway, when it hits a collection-belt guide-bar, when it is dropped on to a grading machine bobbin or on to the grading table after weight grading and when it hits the end of the grading table or another egg already there (Carter, 1976).

Eggshell strength was described using various variables such as thickness of eggshell, shell stiffness and rupture force (De Ketelaere et al., 2002). The rupture force of hen eggs depends on various factors such as breeding conditions (Lichovníková \& Zeman, 2008), the breed of hen (Máchal, 2002), diet (Lichovníková et al., 2008), egg shape (Havlíček et al., 2008; Nedomová et al., 2009), microstructure (Severa et al., 2010a; Severa et al., 2010b), temperature (Voisey \& Hamilton, 1976) and other parameters. This force also depends on loading rate. The data dealing with this effect are rather insufficient. Influence of the loading rate was previously investigated using the most common technique for the measurement of the eggshell strength, when an egg is compressed between two plane plates. It was found that eggshell strength is significantly dependent on the compression rate (Voisey \& Hunt, 1969; Altuntas \& Sekeroglu, 2008). This procedure enables studying of the influence of loading rate in a relatively narrow extent of compression rate. In order to achieve considerably higher loading rates, a new technique of the eggshell strength evaluation under impact loading was developed (Nedomová et al., 2009). The obtained values of the rupture forces were well above those determined under quasi-static compression.

The aim of this paper and research is to use both experimental techniques mentioned above in order to obtain the rupture force of the eggshell in broad spectrum of the loading rates.

\section{Material and Methods}

Eggs (the Hisex Brown strain) were chosen for the experiment. Hens were kept in cage technology at a commercial breeding farm in the Czech Republic. Eggs were collected from hens that were 75 weeks old. 
Defective eggs were sorted and not included in the experiment.

Length $(L)$ and width $(B)$ of eggs were measured with a digital caliper to the nearest $0.01 \mathrm{~mm}$. The unit mass of each egg was weighed with an electronic balance to the nearest $0.001 \mathrm{~g}$. The eggshell shape was described using the shape index (SI), which is defined as:

$$
S I=\frac{B}{L} \times 100 \quad(\%)
$$

where $B$ is the width and $L$ the length of the eggs. Eggs are characterized by the SI as sharp, normal (standard) and round if they have an SI value of $<72$, between 72 and 76, and $>76$, respectively. Because of the strong dependence of the rupture force on the egg shape (Anderson et al., 2004; Altuntaş \& Şekeroğlu, 2008; Nedomová et al., 2009) only the round eggs were used for performed experiments. The geometric mean diameter of eggs is then calculated using the following equation given by Mohsenin (1970):

$$
D_{g}=\left(L B^{2}\right)^{\frac{1}{3}}
$$

According to Mohsenin (1970), the degree of sphericity of eggs can be expressed as follows:

$$
\Phi=\frac{D_{g}}{L} \times 100 \quad(\%)
$$

The surface area of eggs was calculated using the following relationship given by Mohsenin (1970):

$$
S=\pi D_{g}^{2}
$$

Volume of the egg is then given as

$$
V=\frac{\pi}{6} L B^{2}
$$

Volume and surface of the eggs were also evaluated using more accurate formula derived by Narushin (2005):

$$
\begin{gathered}
V=(0.6057-0.0018 B) L B^{2} \\
S=(3.155-0.013 L+0.0115 B) L B
\end{gathered}
$$

In order to obtain an exact description of the egg shape, the digital photos of the eggs were taken. An Olympus SP-560UZ digital camera (Olympus, Japan) was used to capture the pictures. The camera was fixed to the stand and artificial light source was used. The camera-object distance was $50 \mathrm{~cm}$. In order to get the highest possible contrast, the black background was used. The software MATLAB ${ }^{\circledR}$ v. 7.1.0.246 (R14) Service Pack 3 (The MathWorks, Inc., USA) was used to perform the image analysis and for evaluation of the coordinates $x_{i}$ and $y_{i}$ of the egg contour. The geometric characteristics can be also described by alternative procedures, described e.g. in Babić et al. (2011).

In case of mechanical properties, two experimental approaches were used and set of 120 eggs was analyzed.

Approach 1: The eggs were compressed between two plates using universal testing machine TIRATEST 27025, (TIRA GmbH, Deutschland). The compression speed $0.0167 \mathrm{~m} / \mathrm{s}$ is the minimum value achievable at the TIRA test. The egg sample was placed on the fixed plate, loaded at one of compression speeds $(0.0167,0.167$ and 1.67 $\mathrm{mm} / \mathrm{s}$ ) and pressed with a moving plate connected to the load cell until its rupture. Two mutually perpendicular compression axes (corresponding to main geometrical axes) were used to determine the rupture force, specific rupture deformation, and rupture energy.

Approach 2: Significantly higher loading rates were achieved using the experimental technique described in Nedomová et al. (2009). The experimental set-up consists of three major components: the egg support, loading device, and response-measuring device. The eggs were loaded by impact of a free-falling cylindrical bar ( $6 \mathrm{~mm}$ in diameter, $200 \mathrm{~mm}$ in length, made from aluminum alloy). Surface displacement and surface velocity were detected by laser vibrometer POLYTEC CLV 2000 on the equator line of the egg sample. The impacting bar in 
three positions loaded the eggs: sharp end, blunt end, and equator. Impact velocity of the bar was changed (increased) up to the value, at which the eggshell fracture occurred.

Numerical simulation of the experiments was performed using LS DYNA 3D finite element code.

\section{Results and Discussion}

\subsection{Geometrical Parameters}

The egg contours were reconstructed from the digital data by means of method described in previous section. It was shown, see e.g. Nedomová et al. (2009) that this procedure leads to an excellent agreement between experimental eggshell contour and the fitted one. Knowledge of the analytical description of the eggshell contour curve enables evaluation of the radius of the curvature $R$, egg volume and egg surface. The obtained data are presented in Table 1. The values of calculated curvature radii are listed in Table 2. The radii were evaluated at the sharp end, blunt end, and at the maximum width of the egg (equator). Standard deviation value belongs in case of both tables to the mean value.

Table 1. Selected geometrical characteristics of the tested eggs. Standard deviation value belongs to mean value

\begin{tabular}{llllll}
\hline & Characteristic & Minimum & Maximum & Mean & St.deviation \\
\hline & Egg mass $(\mathrm{g})$ & 53.66 & 62.42 & 59.69 & 2.03 \\
& Egg length $L(\mathrm{~mm})$ & 51.93 & 57.59 & 55.27 & 1.12 \\
& Egg width $B(\mathrm{~mm})$ & 41.26 & 49.88 & 43.44 & 0.86 \\
& Shape index $S I(\%)$ & 76.02 & 89.09 & 78.62 & 2.07 \\
& Diameter $\mathrm{D}_{\mathrm{g}}(\mathrm{mm})$ & 45.05 & 51.84 & 47.07 & 0.74 \\
& Sphericity $(\%)$ & 83.30 & 92.59 & 85.18 & 1.48 \\
Eq (3) & Egg surface $\left(\mathrm{mm}^{2}\right)$ & 6374.57 & 8442.26 & 6961.09 & 220.63 \\
Eq (4) & Egg volume $\left(\mathrm{mm}^{3}\right)$ & 47857.55 & 72939.37 & 54632.52 & 2618.81 \\
Eq (5) & Egg surface $\left(\mathrm{mm}^{2}\right)$ & 6497.51 & 8422.23 & 7080.29 & 212.14 \\
Eq (6) & Egg volume $\left(\mathrm{mm}^{3}\right)$ & 48526.31 & 71869.12 & 55033.64 & 2480.16 \\
Exact values & Egg surface $\left(\mathrm{mm}^{2}\right)$ & 7162.07 & 19909.47 & 12677.01 & 2914.25 \\
& Egg volume $\left(\mathrm{mm}^{3}\right)$ & 33092.14 & 88512.37 & 55489.24 & 11689.38 \\
\hline
\end{tabular}

Table 2. Radii of curvature. Standard deviation value belongs to mean value

\begin{tabular}{lllll}
\hline Radius of curvature $(\mathrm{mm})$ & Minimum & Maximum & Mean & St.deviation \\
\hline Sharp end & 11.80 & 20.11 & 14.99 & 1.58 \\
Blunt end & 22.90 & 42.14 & 33.11 & 2.88 \\
Egg width & 30.92 & 50.81 & 38.82 & 2.58 \\
\hline
\end{tabular}

\subsubsection{Compression Test}

Response of the egg to compression loading between two parallel plates is characterized by liner increase in the loading force, F, with moving plate displacement. At the moment of eggshell break the loading force rapidly decreases. This behavior was observed in number of researches and described in many; see e.g. De Ketealere et al. (2004) and Lim et al. (2004). Maximum of the loading force is then defined as the rupture force, $F_{r}$. Specific rupture deformation is defined by the following equation:

$$
\varepsilon_{f}=1-\frac{L_{f}}{L}=\frac{D_{f}}{L}
$$

where $L(\mathrm{~mm})$ is the undeformed egg length measured in the direction of the compression axis and $L_{f}(\mathrm{~mm})$ is the deformed egg length measured in the direction of the compression axis (Braga et al., 1999). The orientation 
of axes is shown e.g. in Altuntaş E. and Şekeroğlu A. (2008). $D_{f}=L-L_{f}$ is the eggshell displacement at the point of rupture on the eggshell. Energy absorbed $\left(E_{a}\right)$ by an egg at the moment of rupture is defined as:

$$
E_{a}=\frac{F_{r} D_{r}}{2}
$$

Two egg compression axes $(X$ and $Z$ ) were used for determination of the above-mentioned quantities. Figure 1 shows the sketch of hen's eggshell. The $X$-axis represented loading axis along the length dimension and the $Z$-axis represented the transverse axis covering the width dimension. Two more orientations were considered in case of $X$-axis. The eggs were loaded at the sharp end and at the blunt end. The series of 10 eggs was tested for each orientation. The results are summarized the Tables 3-5.

Table 3. Results of the compression test. Compression velocity $=1 \mathrm{~mm} / \mathrm{min}(0.0167 \mathrm{~mm} / \mathrm{s})$

\begin{tabular}{llllll}
\hline & & $F_{r}(\mathrm{~N})$ & $D_{r}(\mathrm{~mm})$ & $f_{f}(1)$ & $E_{a}(\mathrm{Nmm})$ \\
\hline$X$-axis (blunt) & Minimum & 24.05 & 0.12 & 0.0217 & 1.72 \\
& Maximum & 30.36 & 0.22 & 0.0398 & 3.19 \\
& Mean & 27.47 & 0.16 & 0.0292 & 2.26 \\
& St.deviation & 1.96 & 0.03 & 0.0054 & 0.51 \\
-axis (sharp) & Minimum & 31.05 & 0.09 & 0.0156 & 1.40 \\
& Maximum & 36.40 & 0.21 & 0.0378 & 3.61 \\
& Mean & 33.75 & 0.17 & 0.0300 & 2.88 \\
& St.deviation & 1.82 & 0.03 & 0.0062 & 0.63 \\
& Minimum & 21.57 & 0.18 & 0.0309 & 2.02 \\
& Maximum & 30.30 & 0.22 & 0.0420 & 2.84 \\
& Mean & 24.57 & 0.20 & 0.0355 & 2.43 \\
& St.deviation & 2.43 & 0.02 & 0.0043 & 0.29 \\
\hline
\end{tabular}

Table 4. Results of the compression test. Compression velocity $10 \mathrm{~mm} / \mathrm{min}(0.167 \mathrm{~mm} / \mathrm{s})$

\begin{tabular}{llrrrr}
\hline & \multicolumn{1}{c}{$F_{r}(\mathrm{~N})$} & $D_{r}(\mathrm{~mm})$ & $f(1)$ & $E_{a}(\mathrm{Nmm})$ \\
\hline$X$-axis (blunt) & Minimum & 24.42 & 0.13 & 0.0241 & 1.59 \\
& Maximum & 50.51 & 0.26 & 0.0453 & 6.57 \\
& Mean & 35.97 & 0.17 & 0.0304 & 3.20 \\
& St.deviation & 9.25 & 0.04 & 0.0067 & 1.54 \\
-axis (sharp) & Minimum & 36.87 & 0.14 & 0.0235 & 2.58 \\
& Maximum & 39.68 & 1.55 & 0.2782 & 29.95 \\
& Mean & 38.42 & 0.32 & 0.0563 & 6.13 \\
& St.deviation & 0.84 & 0.43 & 0.0782 & 8.40 \\
& Minimum & 25.66 & 0.09 & 0.0159 & 1.15 \\
& Maximum & 29.82 & 0.28 & 0.0489 & 3.96 \\
& Mean & 27.90 & 0.22 & 0.0391 & 3.08 \\
& St.deviation & 1.50 & 0.06 & 0.0098 & 0.85 \\
\hline
\end{tabular}


Table 5. Results of the compression test. Compression velocity $100 \mathrm{~mm} / \mathrm{min}(1.67 \mathrm{~mm} / \mathrm{s})$

\begin{tabular}{llcccc}
\hline & & $F_{r}(\mathrm{~N})$ & $D_{r}(\mathrm{~mm})$ & $f(1)$ & $E_{a}(\mathrm{Nmm})$ \\
\hline$X$-axis (blunt) & Minimum & 9.37 & 0.09 & 0.0153 & 1.01 \\
& Maximum & 59.88 & 1.52 & 0.2645 & 7.12 \\
& Mean & 36.21 & 0.31 & 0.0545 & 3.91 \\
& St.deviation & 13.78 & 0.43 & 0.0741 & 1.80 \\
-axis (sharp) & Minimum & 40.15 & 0.12 & 0.0212 & 2.64 \\
& Maximum & 55.57 & 0.46 & 0.0819 & 9.23 \\
& Mean & 44.88 & 0.21 & 0.0376 & 4.82 \\
& St.deviation & 4.35 & 0.10 & 0.0179 & 2.31 \\
& Minimum & 27.46 & 0.20 & 0.0333 & 2.83 \\
& Maximum & 31.25 & 0.27 & 0.0476 & 3.93 \\
& Mean & 29.28 & 0.23 & 0.0396 & 3.29 \\
& St.deviation & 1.16 & 0.03 & 0.0046 & 0.39 \\
\hline
\end{tabular}

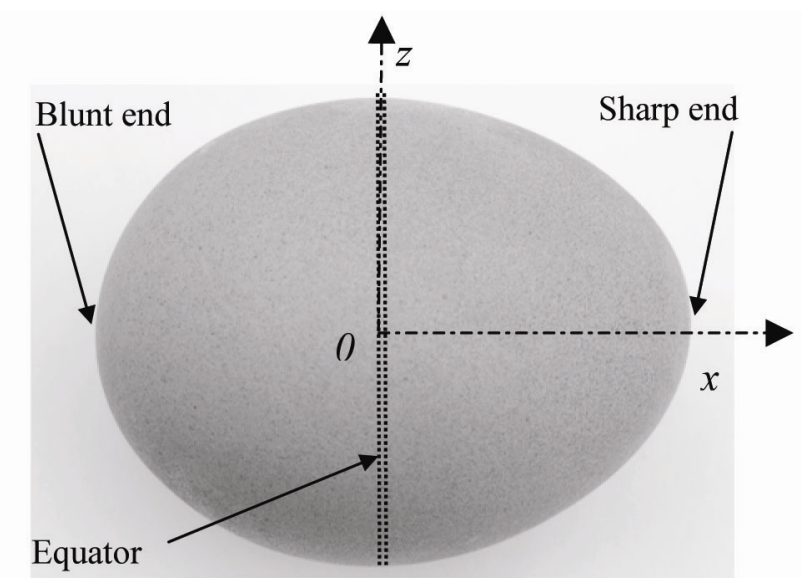

Figure 1. Sketch of hen's eggshell showing the $\mathrm{x}-\mathrm{z}$ axes along with blunt and sharp end and with equator

Increase in the loading rate leads to increase in the rupture force. This result is valid for all orientations and combinations of egg loading. Influence of loading rate on the remaining quantities exhibits the same tendency in previous case. The quantities exhibit their maximum in such loading orientation, when the moving plate is in contact with the sharp end of the egg. These results are generally similar to those obtained by Altuntas and Şekeroğlu (2008). But their validity at higher loading rates is still questionable, because these rates cannot be achieved using the common commercially available universal testing machines. This was the main reason for a use of impact experimental method specified as Approach 2 in the Material and method section.

\subsubsection{Impact Test}

Figure 2 shows an example of the experimental record of the forces in the point of contact between impacting bar and egg. If the eggshell is not damaged the shape of this function is nearly "half-sine". The origin of the eggshell damage is connected with an abrupt in this dependence. The procedure, how to evaluate the rupture force from the dependence of the force maximum on the bar fall height, was discussed in the paper (Nedomová et al., 2009). The results of such analysis are presented in Table 6 . The table contains the corresponding value of the egg fall height and value of impact velocity calculated with use following formula:

$$
v_{o}=\sqrt{2 g h}
$$

where $g$ is the gravity constant. 
Knowledge of the height and/or impact velocity gives no detail information on the velocity of the eggshell loading. It is difficult to detect this process experimentally.

This procedure was used also in Nedomová et al. (2009) and examined in deeper details in Buchar et al. (2010).

Effective way how to describe the eggshell impact loading is numerical simulation. The details of the numerical simulation can be found e.g. in Buchar et al. (2010).

Table 6. Main results of the eggshells impact loading

\begin{tabular}{|c|c|c|c|c|c|c|c|c|c|}
\hline & \multicolumn{3}{|c|}{$\mathrm{X}_{\mathrm{b}}$} & \multicolumn{3}{|c|}{$X_{s}$} & \multicolumn{3}{|c|}{$Z$} \\
\hline & $\mathrm{F}_{\mathrm{r}}(\mathrm{N})$ & $\mathrm{h}(\mathrm{mm})$ & $\mathrm{v}_{\mathrm{r}}(\mathrm{m} / \mathrm{s})$ & $\mathrm{F}_{\mathrm{r}}(\mathrm{N})$ & $\mathrm{h}(\mathrm{mm})$ & $\mathrm{v}_{\mathrm{r}}(\mathrm{m} / \mathrm{s})$ & $\mathrm{F}_{\mathrm{r}}(\mathrm{N})$ & $\mathrm{h}(\mathrm{mm})$ & $\mathrm{v}_{\mathrm{r}}(\mathrm{m} / \mathrm{s})$ \\
\hline & 41.32 & 46.56 & 0.956 & 51.93 & 56.64 & 1.054 & 35.47 & 34.10 & 0.818 \\
\hline & 40.86 & 45.84 & 0.948 & 53.27 & 58.58 & 1.072 & 36.12 & 35.00 & 0.829 \\
\hline & 39.87 & 44.30 & 0.932 & 58.11 & 65.59 & 1.134 & 33.25 & 31.01 & 0.780 \\
\hline & 43.12 & 49.38 & 0.984 & 49.36 & 52.91 & 1.019 & 32.18 & 29.53 & 0.761 \\
\hline & 42.87 & 48.98 & 0.980 & 52.35 & 57.25 & 1.060 & 31.56 & 28.67 & 0.750 \\
\hline & 40.23 & 44.86 & 0.938 & 51.19 & 55.57 & 1.044 & 33.87 & 31.88 & 0.791 \\
\hline & 39.11 & 43.11 & 0.920 & 50.85 & 55.07 & 1.039 & 36.11 & 34.99 & 0.829 \\
\hline & 41.23 & 46.42 & 0.954 & 56.32 & 63.00 & 1.112 & 35.08 & 33.56 & 0.811 \\
\hline & 40.98 & 46.03 & 0.950 & 58.35 & 65.94 & 1.137 & 36.12 & 35.00 & 0.829 \\
\hline & 41.56 & 46.94 & 0.960 & 53.21 & 58.49 & 1.071 & 34.72 & 33.06 & 0.805 \\
\hline Minimum & 39.11 & 43.11 & 0.920 & 49.36 & 52.91 & 1.019 & 31.56 & 28.67 & 0.750 \\
\hline Maximum & 43.12 & 49.38 & 0.984 & 58.35 & 65.94 & 1.137 & 36.12 & 35.00 & 0.829 \\
\hline Mean & 41.12 & 46.24 & 0.952 & 53.49 & 58.90 & 1.074 & 34.45 & 32.68 & 0.800 \\
\hline St.deviation & 1.24 & 1.93 & 0.020 & 3.09 & 4.48 & 0.041 & 1.67 & 2.32 & 0.029 \\
\hline
\end{tabular}

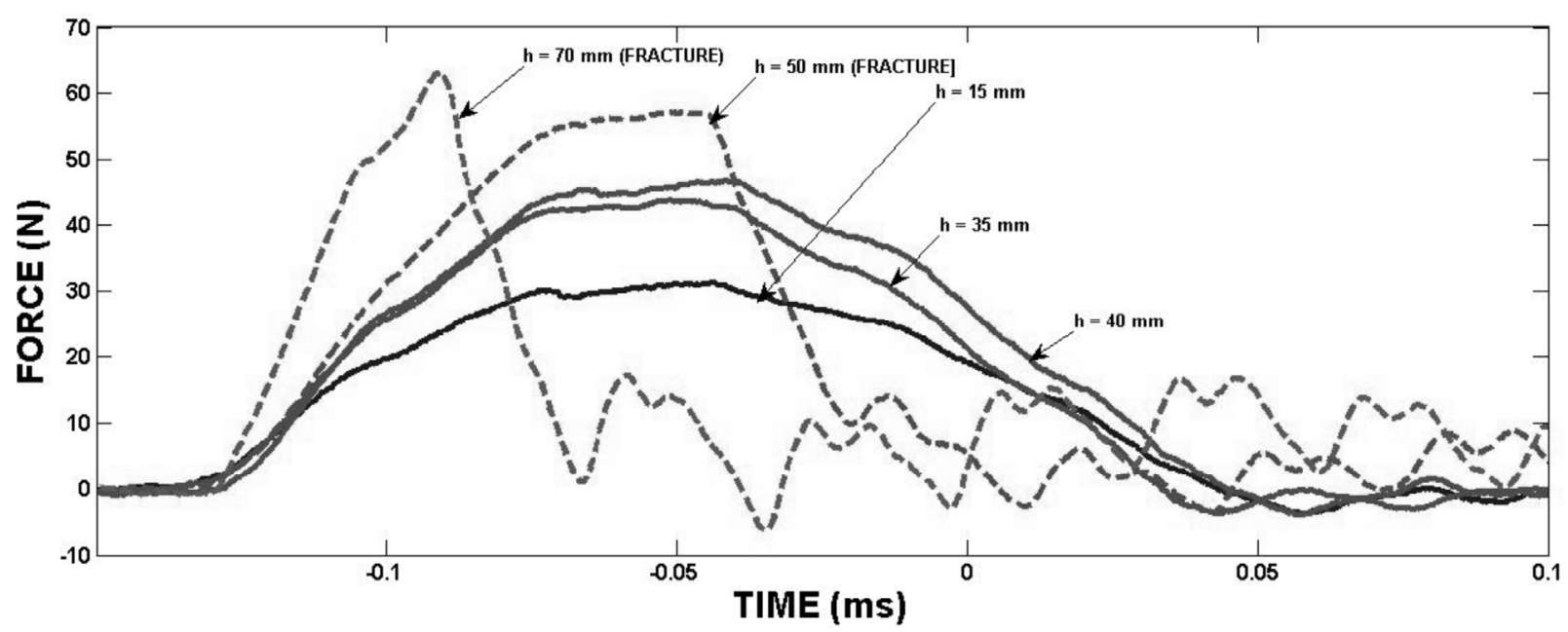

Figure 2. Time dependence of the impact force at different levels of impact velocity. Impact on the sharp egg end

\subsubsection{Numerical Simulation}

Numerical simulation of the experiments described in the previous sections was performed with use of LS DYNA 3D finite element code. The egg models are well described in Buchar et al. (2010). In order to verify the validity of an egg model, the time histories of forces and surface displacements were evaluated. These data can be compared with experimental ones. The results are in general accordance with findings presented in Nedomová et al. (2009) and Buchar et al. (2010) and show that there is rather good agreement between 
experimental records and numerical results. Figure 3 shows an example of the computed eggshell displacement. Selected impact velocity $0.7 \mathrm{~m} / \mathrm{s}$ corresponds to height of fall, $\mathrm{h}=25 \mathrm{~mm}$. No eggshell damage was observed at these loading conditions. Corresponding velocities of the eggshell surface at the bar-egg contact point are displayed in Figure 4.
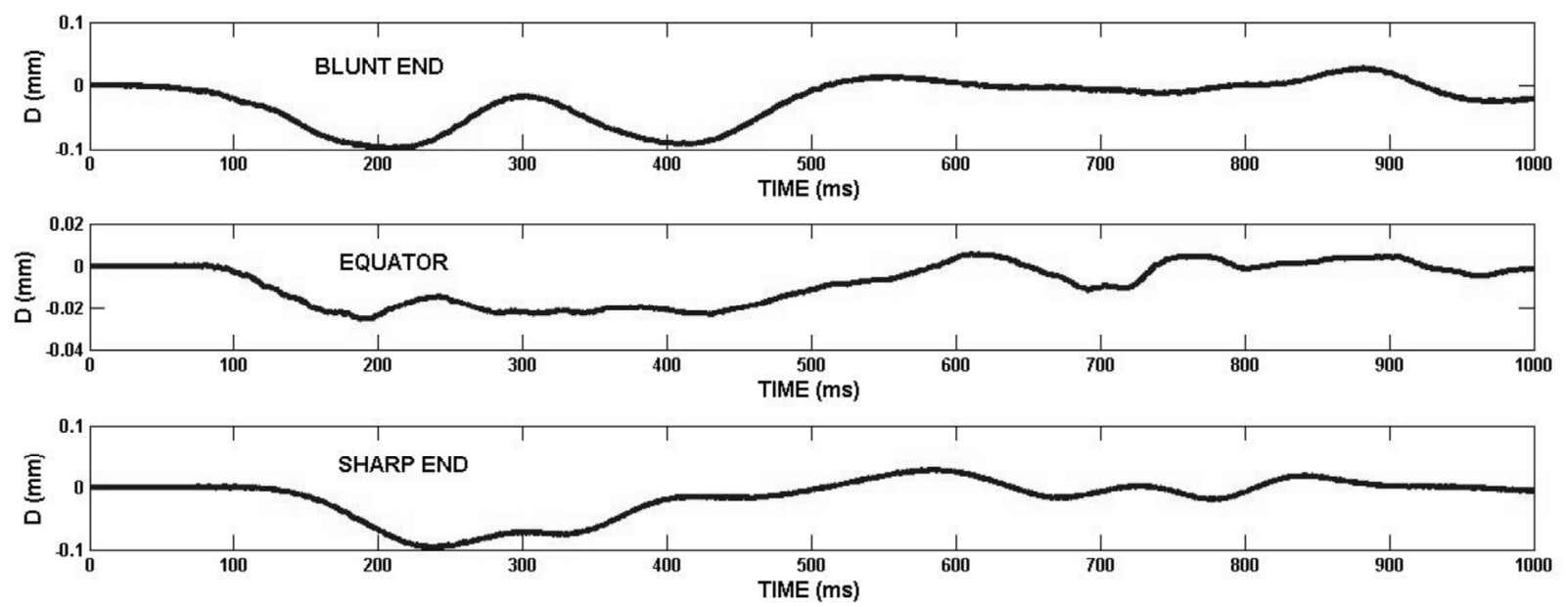

Figure 3. Time histories of the eggshell displacements $(D)$
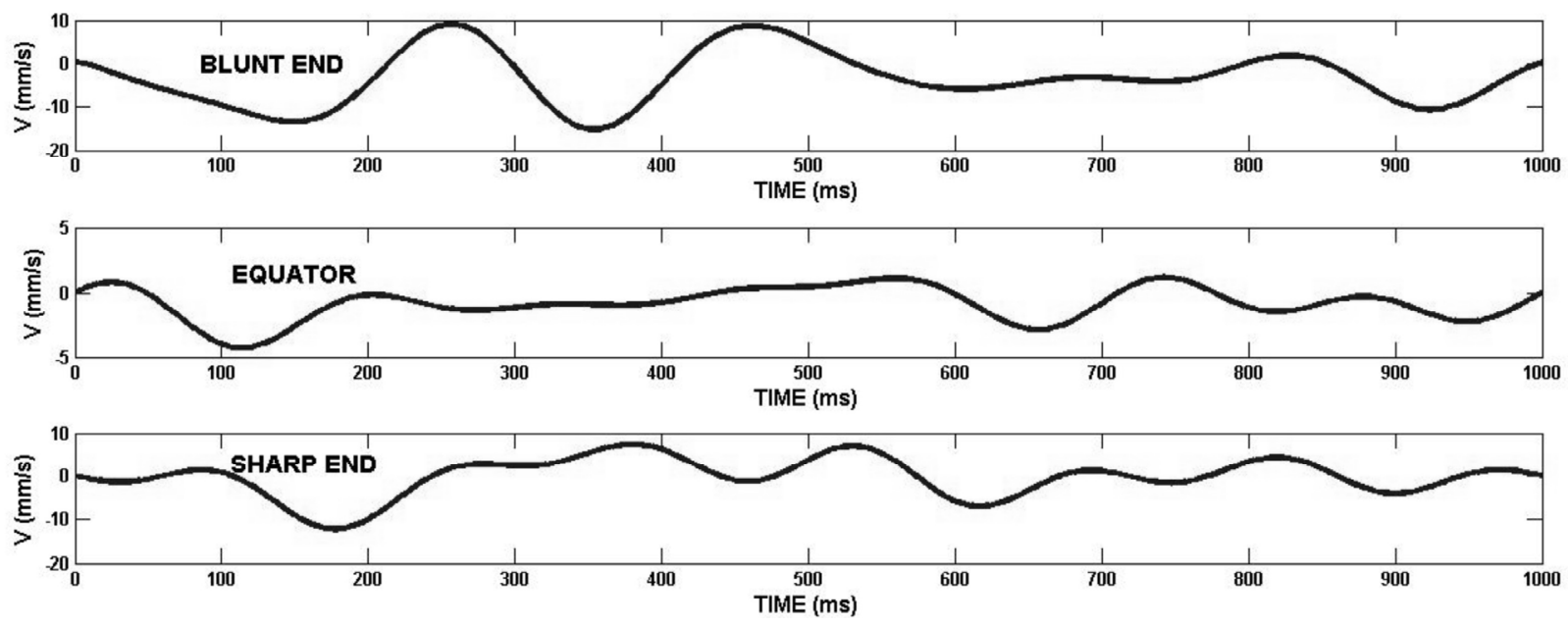

Figure 4. Eggshell surface velocities $(V)$

The numerical simulations were performed for the impact velocities listed in Table 6 . Value of the velocity at the moment when the force reaches its maximum is taken as the velocity at which the eggshell breaks. These velocities $V_{r}$, are given in the Table 7, together with the values of eggshell surface displacements, $D$. Dependence of the rupture force on the loading rate is shown in Figure 5.

Following function can fit the experimental data:

$$
F_{r}=F_{o}+k \ln \left(V_{r}\right)
$$

The parameter $k$ represents a measure of the loading rate sensitivity of the rupture force. The values of function parameters are listed in Table 8. The best fitting contains the data obtained for loading in $X_{a}$ direction. Loading of the sharp end is also connected with the highest sensitivity of the rupture force to the loading rate. The lowest sensitivity was observed for the loading in $Z$ direction. 
Table 7. Numerical results

\begin{tabular}{|c|c|c|c|c|c|c|c|c|c|}
\hline & \multicolumn{3}{|c|}{$\mathrm{X}_{\mathrm{b}}$} & \multicolumn{3}{|c|}{$\mathrm{X}_{\mathrm{s}}$} & \multicolumn{3}{|c|}{$Z$} \\
\hline & $\mathrm{F}_{\mathrm{r}}(\mathrm{N})$ & $\mathrm{D}(\mathrm{mm})$ & $\begin{array}{c}\mathrm{V}_{\mathrm{r}} \\
(\mathrm{mm} / \mathrm{s})\end{array}$ & $\mathrm{F}_{\mathrm{r}}(\mathrm{N})$ & $\mathrm{D}(\mathrm{mm})$ & $\begin{array}{c}\mathrm{V}_{\mathrm{r}} \\
(\mathrm{mm} / \mathrm{s})\end{array}$ & $\mathrm{F}_{\mathrm{r}}(\mathrm{N})$ & $\mathrm{D}(\mathrm{mm})$ & $\begin{array}{c}\mathrm{V}_{\mathrm{r}} \\
(\mathrm{mm} / \mathrm{s})\end{array}$ \\
\hline & 41.32 & 0.130 & 17.200 & 51.93 & 0.115 & 14.300 & 35.47 & 0.060 & 6.500 \\
\hline & 40.86 & 0.135 & 17.200 & 53.27 & 0.125 & 14.300 & 36.12 & 0.060 & 6.700 \\
\hline & 39.87 & 0.130 & 17.300 & 58.11 & 0.120 & 14.200 & 33.25 & 0.050 & 6.700 \\
\hline & 43.12 & 0.150 & 17.500 & 49.36 & 0.120 & 14.100 & 32.18 & 0.070 & 6.600 \\
\hline & 42.87 & 0.145 & 17.100 & 52.35 & 0.120 & 14.100 & 31.56 & 0.070 & 6.700 \\
\hline & 40.23 & 0.145 & 17.500 & 51.19 & 0.115 & 14.300 & 33.87 & 0.070 & 6.700 \\
\hline & 39.11 & 0.135 & 16.900 & 50.85 & 0.125 & 14.500 & 36.11 & 0.060 & 6.500 \\
\hline & 41.23 & 0.165 & 17.200 & 56.32 & 0.125 & 14.300 & 35.08 & 0.060 & 6.500 \\
\hline & 40.98 & 0.140 & 17.600 & 58.35 & 0.125 & 14.200 & 36.12 & 0.060 & 6.500 \\
\hline & 41.56 & 0.140 & 17.500 & 53.21 & 0.120 & 14.200 & 34.72 & 0.050 & 6.500 \\
\hline Minimum & 39.11 & 0.130 & 16.900 & 49.36 & 0.115 & 14.100 & 31.56 & 0.050 & 6.590 \\
\hline Maximum & 43.12 & 0.165 & 17.600 & 58.35 & 0.125 & 14.500 & 36.12 & 0.070 & 6.700 \\
\hline Mean & 41.12 & 0.142 & 17.264 & 53.49 & 0.120 & 14.230 & 34.45 & 0.060 & 6.590 \\
\hline St.deviation & 1.24 & 0.011 & 0.230 & 3.09 & 0.004 & 0.112 & 1.67 & 0.007 & 0.094 \\
\hline
\end{tabular}

Table 8. Parameters of Eq. 10. The symbol $r^{2}$ denotes the correlation coefficient

\begin{tabular}{llll}
\hline & $F_{o}(\mathrm{~N})$ & $k(\mathrm{~N})$ & $r^{2}$ \\
\hline Blunt end & 36.33 & 1.8 & 0.883 \\
Sharp end & 44.61 & 2.906 & 0.978 \\
Equator & 30.38 & 1.494 & 0.895 \\
\hline
\end{tabular}

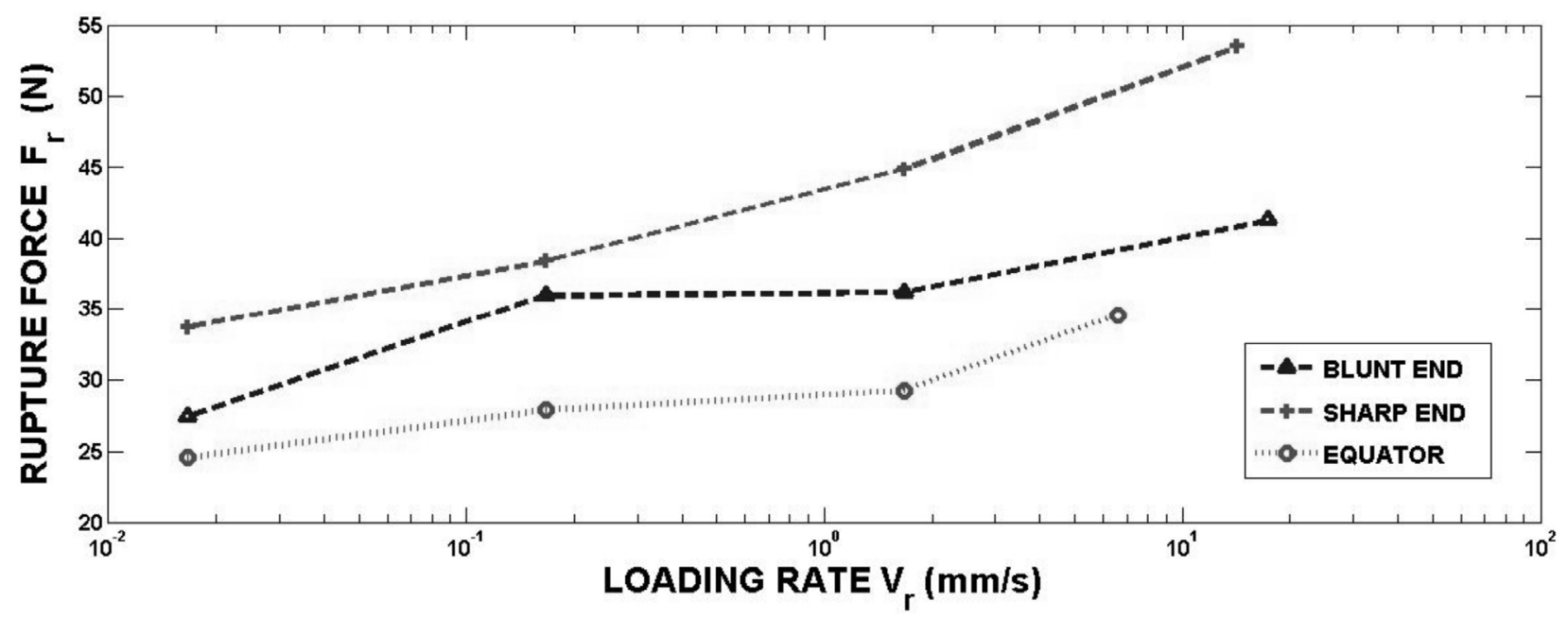

Figure 5. Influence of the loading rate on the rupture force

\section{Conclusions}

(1) The results obtained within presented research show on significant influence of the compression rate on the eggshell rupture force. 
(2) The rupture force increases with the loading rate. This increase was observed in rather broad spectrum of loading (compression) rates ranging from 0.0167 to $17 \mathrm{~mm} / \mathrm{s}$.

(3) The highest rate dependence was observed for loading in the $X_{a}$ direction, while the lowest in the $Z$ direction.

(4) Dependence of the eggshell rupture force on the loading rate can be probably described by a logarithmic function, as it is possible in case of many engineering materials (metals, ceramics, polymeric materials etc.). Contrary to these materials the mechanism of the rate dependence of the eggshell fracture was not fully described up to now.

(5) In order to describe and interpret this mechanism, broad and detailed examination of the eggshell fracture damage is necessary.

\section{Acknowledgment}

The authors would like to acknowledge the support of the Institute of Thermomechanics AS CR, v.v.i through the project Z20760514.

\section{References}

Altuntaş, E., \& Şekeroğlu, A. (2008). Effect of egg shape index on mechanical properties of chicken eggs. Journal of Food Engineering, 85, 606-612. http://dx.doi.org/10.1016/j.jfoodeng.2007.08.022

Anderson, K. E., Tharrington, J. B., Curtis, P. A., \& Jones, F. T. (2004). Shell characteristics of eggs from historic strains of single comb White Leghorn chickens and the relationship of egg shape to shell strength. International Journal of Poultry Science, 3, 17-19. http://dx.doi.org/10.3923/ijps.2004.17.19

Babić, L., Matić-Kekić, S., Dedović, N., Babić, M., \& Pavkov, I. (2011). Surface area and volume modeling of the Williams pear (Pyrus communis). International Journal of Food Properties.

Braga, G. C., Couto, S. M., Hara, T., \& Almeida, Neto, J. T. P. (1999). Mechanical Behaviour of Macadamia Nut under Compression Loading. Journal of Agricultural Engineering Research, 72, 239-245. http://dx.doi.org/10.1006/jaer.1998.0369

Buchar, J., Nedomová, Š., \& Severa, L. (2010). Numerical modelling of the hen's egg behaviour under impact loading. In FOODSIM 2010. Braganca, Portugal, CIMO Research Centre (pp. 159-162).

Carter, T. C. (1976). The hen's egg: Shell forces at impact and quasi-static compression. British Poultry Science, 17, 199-214. http://dx.doi.org/10.1080/00071667608416267

De Ketelaere, B., Bamelis, F., Kemps, B., Decuypere, E., \& De Beardemaeker, J. (2004). Nondestructive measurements of the egg quality. World's Poultry Science Journal, 3, 289-302. http://dx.doi.org/10.1079/WPS200417

De Ketelaere, B., Govaerts T., Coucke, P., Dewil, E., Visscher, J., Decuypere, E., \& De Baerdemaeker, J. (2002). Measuring the eggshell strength of 6 different genetic strains of laying hens: Techniques and comparisons. British Poultry Science, 43, 238-244. http://dx.doi.org/10.1080/00071660120121454

Havlíček, M., Nedomová, Š., Simeonovová, J., Severa, L., \& Křivánek, I. (2008). On the evaluation of chicken egg shape variability. Acta Universitatis agriculture et silviculture Mendelianae Brunensis, 5, 69-74.

Lichovníková, M., \& Zeman, L. (2008). Effect of housing system on the calcium requirement of laying hens and on eggsehll quality. Czech Journal of Animal Science, 53, 162-168.

Lichovníková, M., Zeman, L., \& Jandásek, J. (2008). The effect of feeding untreated rapeseed and iodine supplement on egg quality. Czech Journal of Animal Science, 53, 77-82.

Lin, H., Mertens, K., Kemps, B., Govaerts, T., De Ketelaere, B., De Baerdemaeker, J., ... Buyse, J. (2004). New approach of testing the effect of heat stress on eggshell quality: mechanical and material properties of eggshell and membrane. British Poultry Science, 45, 476-482. http://dx.doi.org/10.1080/00071660400001173

Máchal, L. (2002). The relationship of shortening and strength of eggshell to some egg quality indicators and egg production in hens of different initial laying lines. Archives of animal breeding, 3, 287-296.

Mohsenin, N. N. (1970). Physical properties of plant and animal material. Gordon and Breach, New York.

Narushin, V. G. (2005). Egg geometry calculation using the measurements of length and breadth. Poultry Science, 3, 482-484. 
Nedomová, Š., Severa, L., \& Buchar, J. (2009). Influence of hen egg shape on eggshell compressive strength. International Agrophysics, 23, 249-256.

Severa, L., Buchar, J., Němeček, J., \& Nedomová, Š. (2010). Nanoindentation as a new tool for evaluation of hen's eggshell local mechanical properties, Chemické listy, 15, 368-370.

Severa, L., Němeček, J., Nedomová, Š., \& Buchar, J. (2010). Determination of micromechanical properties of a hen's eggshell by means of nanoindentation. Journal of Food Engineering, 2, 146-151. http://dx.doi.org/10.1016/j.jfoodeng.2010.06.013

Voisey, P. W., \& Hamilton, J. R. (1976). Factors affecting the non-destructive and destructive methods of measuring egg shell strength by the quasi-static compression test 1. British Poultry Science, 17, 103-124. http://dx.doi.org/10.1080/00071667608416254

Voisey, P. W., \& Hunt, J. R. (1969). Effect of compression speed on the behaviour of eggshells. Journal of Agricultural Engineering Research, 14, 40-46. http://dx.doi.org/10.1016/0021-8634(69)90065-1 